\title{
Six-minute stepper test: a valid clinical exercise tolerance test for COPD patients
}

\author{
This article was published in the following Dove Press journal: \\ International Journal of COPD \\ 29 March 2016 \\ Number of times this article has been viewed
}

\author{
JM Grosbois ${ }^{1,2}$ \\ C Riquier ${ }^{3}$ \\ B Chehere ${ }^{4}$ \\ J Coquart ${ }^{5}$ \\ H Béhal ${ }^{6}$ \\ $F$ Bart $^{2}$ \\ B Wallaert ${ }^{2,3}$ \\ C Chenivesse ${ }^{3}$
}

'FormAction Santé, Pérenchies, France; ${ }^{2}$ Department of Respiratory Medicine, Centre Hospitalier

Germon et Gauthier, Béthune, France; ${ }^{3}$ Department of Respiratory Medicine Immunology and Allergy, Centre Hospitalier Universitaire de Lille, Competence Center for rare lung diseases, University Lille 2, Lille, France; ${ }^{4}$ EA 7369, URePSSS, Multidisciplinary Research Unit in Sport Health Society, University Lille 2, Lille, France; ${ }^{5}$ Faculty of Sport Sciences, Sports and Physical Activity, Center for Ecology and Transformation, University of Rouen, Mont Saint Aignan, France; ${ }^{6}$ Department of Statistical Methods and Biostatistics, Centre Hospitalier Universitaire de Lille, University of Lille Nord, Lille, France
Correspondence: JM Grosbois Service de Pneumologie, Centre Hospitalier Germon et Gauthier, Béthune 62408, France

Email jmgrosbois@formactionsante.com
Introduction: Exercise tolerance testing is an integral part of the pulmonary rehabilitation (PR) management of patients with chronic obstructive pulmonary disease (COPD). The 6-minute stepper test (6MST) is a new, well-tolerated, reproducible exercise test, which can be performed without any spatial constraints.

Objective: The aim of this study was to compare the results of the 6MST to those obtained during a 6-minute walk test (6MWT) and cardiopulmonary exercise testing (CPET) in a cohort of COPD patients.

Methods: Ninety-one COPD patients managed by outpatient PR and assessed by 6MST, 6MWT, and CPET were retrospectively included in this study. Correlations between the number of steps on the 6MST, the distance covered on the 6MWT, oxygen consumption, and power at the ventilatory threshold and at maximum effort during CPET were analyzed before starting PR, and the improvement on the 6MST and 6MWT was compared after PR.

Results: The number of steps on the 6MST was significantly correlated with the distance covered on the 6MWT ( $r=0.56 ; P<0.0001)$, the power at maximum effort $(r=0.46 ; P<0.0001)$, and oxygen consumption at maximum effort $(r=0.39 ; P<0.005)$. Performances on the $6 \mathrm{MST}$ and 6MWT were significantly improved after PR (570 vs 488 steps, $P=0.001$ and 448 vs $406 \mathrm{~m}$, respectively; $P<0.0001$ ). Improvements of the 6MST and 6MWT after PR were significantly correlated $(r=0.34 ; P=0.03)$.

Conclusion: The results of this study show that the $6 \mathrm{MST}$ is a valid test to evaluate exercise tolerance in COPD patients. The use of this test in clinical practice appears to be particularly relevant for the assessment of patients managed by home PR.

Keywords: 6-minute stepper test, 6-minute walk test, exercise tolerance, pulmonary rehabilitation, cardiopulmonary exercise testing, validity

\section{Introduction}

Chronic obstructive pulmonary disease (COPD) is a chronic lung disease marked by breathlessness on exertion, with systemic consequences and an increased risk of disability and death, especially as COPD is frequently associated with comorbidities (cardiovascular disease, obesity, and Type 2 diabetes). ${ }^{1,2}$ Pulmonary rehabilitation (PR), comprising exercise retraining, resumption of physical activity, therapeutic education, and psychosocial support, is an integral part of the management of COPD patients. This global management allows improvement of dyspnea, exercise tolerance, and quality of life. ${ }^{3-6}$

Various exercise tests are commonly used to assess the exercise tolerance of patients with lung disease in the context of PR. Cardiopulmonary exercise testing (CPET) is the standard test allowing investigation of the pathophysiological mechanisms responsible for dyspnea and evaluation of aerobic capacity. ${ }^{7}$ However, CPET requires specialized and expensive equipment and qualified personnel, which limit its availability. The 6-minute 
walk test (6MWT) is a validated test for most chronic lung diseases; it is easy to perform and does not require any specific equipment. The 6MWT is sensitive and reproducible and is commonly used to evaluate the course of exercise tolerance in the context of out/inpatient PR with a well-defined minimal clinically important difference. ${ }^{8-11}$ According to the American Thoracic Society (ATS) guidelines, ${ }^{12}$ the $6 \mathrm{MWT}$ must be performed in an unobstructed $30 \mathrm{~m}$ hallway, but such a space is rarely available in the patient's home ${ }^{13}$ or in the physician's office, or even in some respiratory medicine departments. A recent study has however proposed performing the 6MWT over a distance of $10 \mathrm{~m}^{14}$

To overcome these technical and spatial limitations, a 6-minute stepper test (6MST) has been proposed to evaluate exercise tolerance. This test requires only a limited amount of space and equipment and is feasible, easy to perform, sensitive, well tolerated, and reproducible in COPD patients. ${ }^{15,16}$ The 6MST has been used to assess exercise tolerance in the context of PR. ${ }^{17,18}$ However, the correlation between the 6MST and validated indices used to measure exercise capacity (6MWT and CPET) has not yet been established.

The primary objective of this study was to analyze the correlations between exercise tolerance data provided by the 6MST, 6MWT, and CPET in a population of COPD patients managed by outpatient PR. The secondary objective was to analyze and compare the course of exercise tolerance measured by $6 \mathrm{MST}$ and $6 \mathrm{MWT}$ before and after PR.

\section{Material and methods}

This monocentric retrospective study included COPD patients managed by outpatient PR. Patients included in this study were those who had completed the entire PR program and those for whom pre-rehabilitation 6MWT, 6MST, and CPET assessment data were available.

The severity of COPD was evaluated by Global Initiative for Chronic Obstructive Lung Disease (GOLD) stage. ${ }^{19}$ Patients were divided into two groups according to GOLD stage: mild-to-moderate COPD (Stages 1 and 2) and severeto-very-severe COPD (Stages 3 and 4).

All data were collected prospectively and were entered into our rehabilitation computerized medical records. The study protocol was approved by the Observational Research Protocol Evaluation Committee of the French Language Society of Pulmonology, France. As the study data was collected as part of a pulmonary rehabilitation program prior to this retrospective study commencing the Observational Research Protocol Evaluation Committee advised written informed consent did not need to be obtained from the patients.

\section{Pulmonary function tests}

Spirometry was performed before PR in clinically stable patients, according to European guidelines. ${ }^{20,21}$

\section{Cardiopulmonary exercise testing}

CPET was performed according to an incremental protocol on a cycle ergometer (Ergometrics 800; ergoline, Bitz, Germany), with blood pressure and electrocardiographic monitoring (Medcard; Medisoft ${ }^{\circledR}$, Dinant, Belgium), according to the usual guidelines..$^{22,23}$ The protocol included a 3-minute rest period, a 3-minute unloaded pedaling period, an incremental ramp exercise (10-15 W/min) pursued to a symptom-limited end point, and a 3-minute recovery time. Inspired and expired gases were collected by a mouthpiece connected to a gas analyzer (Ergocard, Medisoft $\left.{ }^{\circledR}\right)$. Maximal oxygen consumption $\left(\mathrm{VO}_{2 \max }\right)$ and oxygen consumption at the ventilatory threshold (VT) were expressed in $\mathrm{mL} / \mathrm{min} / \mathrm{kg}$. VT was defined by a nonlinear increase in ventilation $\left(\mathrm{V}_{\mathrm{E}}\right)$ during exercise and was determined by the level of effort at which carbon dioxide production $\left(\mathrm{VCO}_{2}\right)$ increased more rapidly than $\mathrm{VO}_{2},{ }^{24}$ or by an increase in the respiratory equivalent for oxygen $\left(\mathrm{V}_{\mathrm{E}} / \mathrm{VO}_{2}\right)$ with no increase in the respiratory equivalent for carbon dioxide $\left(\mathrm{V}_{\mathrm{E}} / \mathrm{VCO}_{2}\right) .{ }^{25}$ All CPET were limited by dyspnea, fatigue, or both and provided at least one objective criterion of maximum among the following: breathing reserve $<15 \%$, peak heart rate $>90 \%$ of predicted, peak lactate $>7$ $\mathrm{mEq} / \mathrm{L}$, peak exercise partial pressure of oxygen $\left(\mathrm{PaO}_{2}\right)$ in arterial blood $<55 \mathrm{mmHg}$, or peak $\mathrm{V}_{\mathrm{E}} / \mathrm{VO}_{2}>35$. $^{22}$

\section{Six-minute walk test}

The 6MWT was performed over a "rectangular" distance of $70 \mathrm{~m}$ in the respiratory medicine department. With the exception of this point, the ATS guidelines for 6MWT were followed. ${ }^{12}$ After resting for 5 minutes, continuous monitoring of transcutaneous oxygen saturation $\left(\mathrm{SpO}_{2}\right)$ and heart rate by a pulse oximeter (Oxymontre 3100; Nonin ${ }^{\circledR}$, Plymouth, MN, USA) were performed.

\section{Six-minute stepper test}

The 6MST aims at measuring the number of steps performed on a stepper in 6 minutes using a protocol that is equivalent to the 6MWT protocol. A step was defined as a single complete movement of raising one foot and putting it down. The stepper (Go Sport $^{\circledR}$, Grenoble, France) ${ }^{16}$ was placed on the ground facing a wall to allow patients to maintain their balance by 
placing their fingers on the wall. The step height was set at $20 \mathrm{~cm}$. Before starting the test, patients got accustomed to the stepper for 2 minutes. The protocol included a 3-minute rest period and a 6-minute stepping period. Patients received standardized instructions adapted from the 6MWT ATS instructions, ${ }^{15}$ advising them to make the most number of steps they could in 6 minutes. The number of steps performed in 6 minutes was recorded. Monitoring of heart rate and $\mathrm{SpO}_{2}$ by a pulse oximeter (Oxymontre 3100; Nonin) was performed each minute. An investigator, a member of the paramedical team, remained behind the patient throughout the test.

The 6MST and 6MWT were conducted by the same team to avoid between-investigator variability.

\section{Pulmonary rehabilitation}

Patients completed a 6-week course of outpatient PR at a rate of four sessions per week, 3 hours per session, comprising a combination of exercise retraining, therapeutic education, and psychosocial support. ${ }^{6,17}$

\section{Statistical analysis}

Statistical analysis was performed with PRISM software $\left(\mathrm{GraphPad}^{\circledR}\right.$, La Jolla, CA, USA) and SAS version 9.3 software (SAS Institute, Cary, NC, USA). Quantitative parameters were expressed in terms of mean and standard deviation. Qualitative parameters were expressed in terms of frequencies and percentages. The distribution of quantitative parameters was verified graphically and by a Shapiro-Wilk test.

Pearson's or Spearman's correlation coefficient was used to evaluate the correlation between the results of the various tests performed by the patients (CPET, 6MWT, and 6MST). A linear regression was performed to analyze the independent correlation between the 6MST (dependent variable) and the 6MWT distance according to age, body mass index, forced expiratory volume in one second/forced vital capacity (independent variables).

Student's $t$-test for paired data or Wilcoxon signed rank test was used to compare the course of the 6MST and 6MWT results before and after PR, according to the distribution of the variables. All tests were initially performed on the overall population, and then according to the severity of COPD exclusively for the 6MST and 6MWT results. The significance level was set at $5 \%$.

\section{Results}

One hundred seventy-seven COPD patients were managed by outpatient PR between January 2010 and December 2014. Ninety-one (51\%) of these patients completed a pre-rehabilitation assessment comprising all three tests
Table I Patient characteristics $(n=91)$

\begin{tabular}{|c|c|}
\hline Male $^{a}$ & $76(83.5)$ \\
\hline Age $(\text { years })^{b}$ & $60.3 \pm 9.3$ \\
\hline Current smoker & $8(9)$ \\
\hline Ex-smoker & $83(91)$ \\
\hline \multicolumn{2}{|l|}{ COPD stage $\mathrm{e}^{\mathrm{a}}$} \\
\hline GOLD I & $7(8)$ \\
\hline GOLD 2 & $53(58)$ \\
\hline GOLD 3 & $20(22)$ \\
\hline GOLD 4 & II (I2) \\
\hline BODE Index & $3.7 \pm 1.82$ \\
\hline LTOT $^{\mathrm{a}}$ & $4(4)$ \\
\hline $\mathrm{NIV}^{\mathrm{a}}$ & $I(I)$ \\
\hline $\mathrm{FVC}(\mathrm{L})^{\mathrm{b}}$ & $2.89 \pm 0.85$ \\
\hline FVC (\% predicted $)^{b}$ & $73 \pm 24$ \\
\hline $\mathrm{FEV}_{1}(\mathrm{~L})^{\mathrm{b}}$ & $1.69 \pm 0.59$ \\
\hline $\mathrm{FEV}_{1}(\% \text { predicted })^{\mathrm{b}}$ & $55 \pm 19$ \\
\hline $\mathrm{FEV}_{1} / \mathrm{FVC}(\%)^{\mathrm{b}}$ & $58.2 \pm 11.7$ \\
\hline BMI $\left(\mathrm{kg} / \mathrm{m}^{2}\right)^{\mathrm{b}}$ & $27.3 \pm 6.3$ \\
\hline$>30^{\mathrm{a}}$ & $30(33)$ \\
\hline $25-29.9^{a}$ & $25(27.5)$ \\
\hline $21-24.9^{a}$ & $20(22)$ \\
\hline$<2^{a}$ & $16(17.5)$ \\
\hline Cardiovascular comorbidities ${ }^{a}$ & $60(66)$ \\
\hline Hypertension $^{\mathrm{a}}$ & $26(29)$ \\
\hline Peripheral arterial disease ${ }^{a}$ & $8(8.7)$ \\
\hline Myocardial infarction ${ }^{\mathrm{a}}$ & $7(8)$ \\
\hline Diabetes $^{\mathrm{a}}$ & II (I2) \\
\hline
\end{tabular}

(6MST, 6MWT, and CPET) and were included in this study. Another 86 patients (49\%) were excluded due to missing CPET ( $n=39)$ or 6 MWT data $(n=21)$, or because a stress test rather than CPET was performed $(\mathrm{n}=26)$. The characteristics of the 91 patients are presented in Table 1.

A statistically significant correlation was observed between the number of steps on the 6MST and the distance covered on the 6MWT $(r=0.56 ; P<0.0001$; Figure 1$)$,

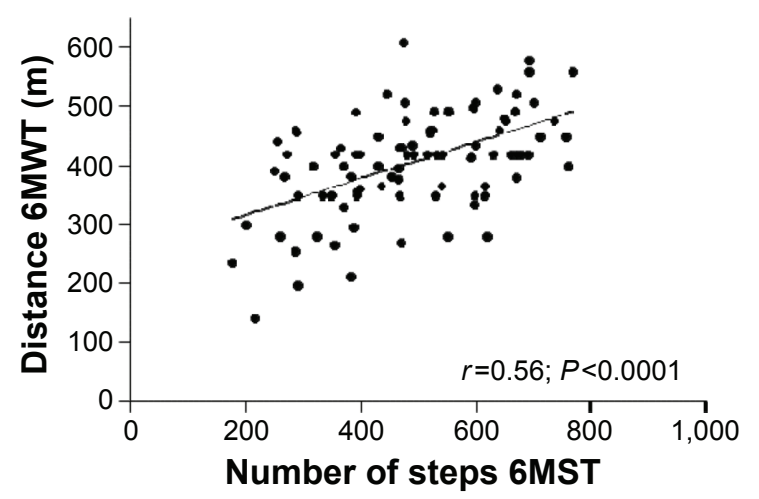

Figure I Correlation between the number of steps on the 6MST and the distance covered on the 6MWT before PR.

Abbreviations: 6MST, 6-minute stepper test; 6MWT, 6-minute walk test; PR, pulmonary rehabilitation. 
Table 2 Test results before PR and correlations

\begin{tabular}{|c|c|c|c|c|c|}
\hline \multirow[t]{2}{*}{ Test parameters } & \multicolumn{3}{|c|}{ Correlation with 6MST } & \multicolumn{2}{|c|}{ Correlation with 6MWT } \\
\hline & $\begin{array}{l}\text { All }(n=9 I), \\
\text { mean } \pm \text { SD }\end{array}$ & $r$ & $P$-value & $r$ & $P$-value \\
\hline 6MST (steps) & $488 \pm 149$ & NA & NA & 0.56 & $<0.0001$ \\
\hline 6MWT (m) & $406 \pm 86$ & 0.56 & $<0.0001$ & NA & NA \\
\hline Power-VT (W) & $52 \pm 23$ & 0.36 & $<0.005$ & 0.32 & 0.009 \\
\hline $\mathrm{VO}_{2}-\mathrm{VT}(\mathrm{mL} / \mathrm{min} / \mathrm{kg})$ & $11.4 \pm 3.3$ & 0.26 & NS & 0.35 & 0.001 \\
\hline Power-max (W) & $86 \pm 33$ & 0.46 & $<0.0001$ & 0.39 & 0.0002 \\
\hline $\mathrm{VO}_{2 \max }(\mathrm{mL} / \mathrm{min} / \mathrm{kg})$ & $15.2 \pm 4.8$ & 0.39 & $<0.005$ & 0.38 & 0.03 \\
\hline
\end{tabular}

Abbreviations: PR, pulmonary rehabilitation; 6MST, 6-minute stepper test; 6MWT, 6-minute walk test; $\mathrm{VO}_{2}-\mathrm{VT}_{\text {, oxygen }}$ consumption at ventilatory threshold; $\mathrm{VO}_{2}$ max' oxygen consumption at maximum effort; Power-VT, Power at ventilatory threshold; Power-max, Power at maximum effort; NA, not applicable; NS, not significant.

independent of the severity of COPD (Table 2). This correlation was observed in patients with mild-to-moderate COPD and in patients with severe-to-very-severe COPD (Table 3). The number of steps on the 6MST was correlated with power (W) at the VT and at maximum effort, and $\mathrm{VO}_{2 \max }$ (Tables 2 and 4). Similarly, the distance covered on the 6MWT was correlated with power and $\mathrm{VO}_{2}$ at the VT and at $\mathrm{VO}_{2 \max }$ (Table 2). A linear regression showed that the $6 \mathrm{MST}$ was related to the 6MWT distance and peak exercise power, independent of age, lung function, and body mass index (Table 4).

For the overall population, a significant improvement of the 6MWT distance was observed, increasing from $406 \pm 86 \mathrm{~m}$ before PR to $448 \pm 95 \mathrm{~m}$ after PR $(P<0.0001)$, together with a significant increase in the number of steps on the $6 \mathrm{MST}$, increasing from $488 \pm 149$ steps before PR to $570 \pm 161$ steps after PR $(P<0.0001)$. A statistically significant correlation was observed for all patients between the number of steps on the 6MST and the distance covered on the 6MWT after PR $(r=0.75 ; P<0.0001 ;$ Figure 2). Subgroup analysis revealed similar results for patients with mild-to-moderate COPD $(r=0.77 ; P<0.0001)$ and patients with severe-to-very-severe $\operatorname{COPD}(r=0.76 ; P<0.0001)$. As shown in Figure 3, improvement of the 6MST after PR was correlated with improvement of the 6MWT in all patients (absolute values: $r=0.34 ; P=0.03$; Figure 3; percentage change: $r=0.32 ; P=0.001$ ).

\section{Discussion}

This study shows that the number of steps on the 6MST was significantly correlated with the distance covered on the $6 \mathrm{MWT}, \mathrm{VO}_{2 \max }$, and power at VT and at maximum effort, independent of the severity of COPD. These results also show a significant correlation between improvements of performances on the 6MWT and 6MST after outpatient PR.

Assessment of exercise tolerance is an integral part of the evaluation of COPD patients during PR., ${ }^{4,6}$ Despite the demonstrated value of the 6MWT, its technical constraints do not always allow use and regular repetition of this test during patient follow-up, especially in the physician's or physiotherapist's office, or at the patient's home. ${ }^{12,13}$ Consequently, various teams have developed alternatives to these tests, including the 6MST.

In line with previous studies, ${ }^{15,26}$ our results demonstrated a significant correlation between the number of steps on the 6MST and the distance covered on the 6MWT. These correlations were independent of the severity of COPD. Delourme et $\mathrm{al}^{26}$ also showed that these correlations remained significant independent of the type of interstitial lung disease (ILD). All of these results indicate that the 6MST can be used in a wide range of patients with varying degrees of severity of chronic lung disease (COPD and ILD).

The 6MWT is considered to be a submaximal test, as the subject is free to walk at his or her own rate, but it has been shown that the most severe COPD patients achieve an

Table 3 Test results before PR according to the severity of COPD and correlations with the 6MST

\begin{tabular}{|c|c|c|c|c|c|c|}
\hline Test parameters & $\begin{array}{l}\text { Stage I and } 2 \text { COPD }(n=60) \text {, } \\
\text { mean } \pm \text { SD }\end{array}$ & $r$ & $P$-value & $\begin{array}{l}\text { Stage } 3 \text { and } 4 \text { COPD }(n=3 I) \text {, } \\
\text { mean } \pm \text { SD }\end{array}$ & $r$ & $P$-value \\
\hline 6MST (steps) & $502.6 \pm 145.9$ & NA & NA & $461.1 \pm 154.5$ & NA & NA \\
\hline 6MWT (m) & $40 I . I \pm 89.3$ & 0.53 & $P<0.0001$ & $4|4.6 \pm 8| .7$ & 0.55 & $P<0.005$ \\
\hline Power-VT (W) & $56.2 \pm 24.08$ & 0.43 & $P<0.005$ & $44.5 \pm 20$ & 0.22 & NS \\
\hline $\mathrm{VO}_{2}-\mathrm{VT}(\mathrm{mL} / \mathrm{min} / \mathrm{kg})$ & $11.5 \pm 3.8$ & 0.15 & NS & $11.1 \pm 2.2$ & 0.52 & $P<0.05$ \\
\hline Power-max (W) & $92.3 \pm 32.3$ & 0.45 & $P<0.0005$ & $73.9 \pm 30$ & 0.44 & $P<0.05$ \\
\hline $\mathrm{VO}_{2 \max }(\mathrm{mL} / \mathrm{min} / \mathrm{kg})$ & $15.7 \pm 5.3$ & 0.29 & NS & $14.4 \pm 3.7$ & 0.62 & $P<0.005$ \\
\hline
\end{tabular}

Abbreviations: PR, pulmonary rehabilitation; 6MST, 6-minute stepper test; 6MWT, 6-minute walk test; $\mathrm{VO}_{2}-\mathrm{VT}_{\text {, oxygen }}$ consumption at ventilatory threshold; $\mathrm{VO}_{2}$, oxygen consumption at maximum effort; Power-VT, Power at ventilatory threshold; Power-max, Power at maximum effort; NA, not applicable; NS, not significant. 
Table 4 Linear regression using the 6MST as a dependent variable

\begin{tabular}{|c|c|c|c|c|}
\hline $\begin{array}{l}\text { Test } \\
\text { parameters }\end{array}$ & Estimate & $\begin{array}{l}\text { Standard } \\
\text { error }\end{array}$ & $P$-value & $\begin{array}{l}\text { Squared partial } \\
\text { correlation }\end{array}$ \\
\hline Power-max (W) & 1.27 & 0.53 & 0.0188 & 0.06 \\
\hline 6MWT (m) & 0.72 & 0.17 & 0.0001 & 0.16 \\
\hline Age (years) & 0.15 & 0.58 & 0.79 & 0.0008 \\
\hline BMI $\left(\mathrm{kg} / \mathrm{m}^{2}\right)$ & -1.60 & 2.52 & 0.52 & 0.005 \\
\hline FEV /FVC (\%) & 152 & 125 & 0.22 & 0.02 \\
\hline
\end{tabular}

Abbreviations: 6MST, 6-minute stepper test; 6MWT, 6-minute walk test; Powermax, power at maximum effort; BMI, body mass index; FVC, forced vital capacity; $\mathrm{FEV}_{1}$, forced expiratory volume in one second.

identical $\mathrm{VO}_{2}$ to that observed at the end of a cycle ergometer test, by the third minute of walking. ${ }^{27-30} \mathrm{McGavin}$ et a ${ }^{31}$ have previously validated the 12MWT in COPD patients based on the significant correlation $(r=0.52)$ between the distance covered and $\mathrm{VO}_{2 \max }$, as also confirmed by Carter et al ${ }^{32}$ and, more recently, by Luxton et $\mathrm{al}^{133}$ ( $r=0.54$ and $r=0.63$, respectively). Similar results have been reported in patients with heart failure $(r=0.42)$ and respiratory insufficiency $(r=0.57))^{34,35}$ This study demonstrated identical correlations between maximum values obtained during CPET and the distance covered on the $6 \mathrm{MWT}$, as well as the number of steps on the 6MST.

Other clinical tests have been proposed in the literature, such as the stair climbing test, ${ }^{36,37}$ the sit-to-stand test, ${ }^{38}$ and the step test (walking up and down a $20 \mathrm{~cm}$ platform for a determined duration). ${ }^{39}$ In a population of COPD patients, the performance on the step test is correlated with the performance on CPET, and the distance covered on the $12 \mathrm{MWT}^{40}$ and the $6 \mathrm{MWT} .{ }^{41} \mathrm{We}$ decided to perform this test on a stepper device rather than on a $20 \mathrm{~cm}$ platform, because the stepper allows the patient to maintain balance by lightly placing the fingers on the wall, which is more reassuring for elderly patients and/or patients with balance disorders.

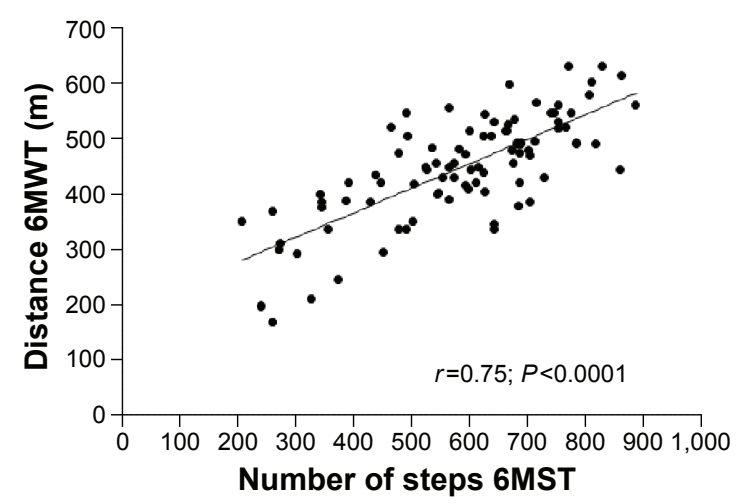

Figure 2 Correlation between the number of steps on the 6MST and the distance covered on the 6MWT after PR.

Abbreviations: 6MST, 6-minute stepper test; 6MWT, 6-minute walk test; PR, pulmonary rehabilitation.

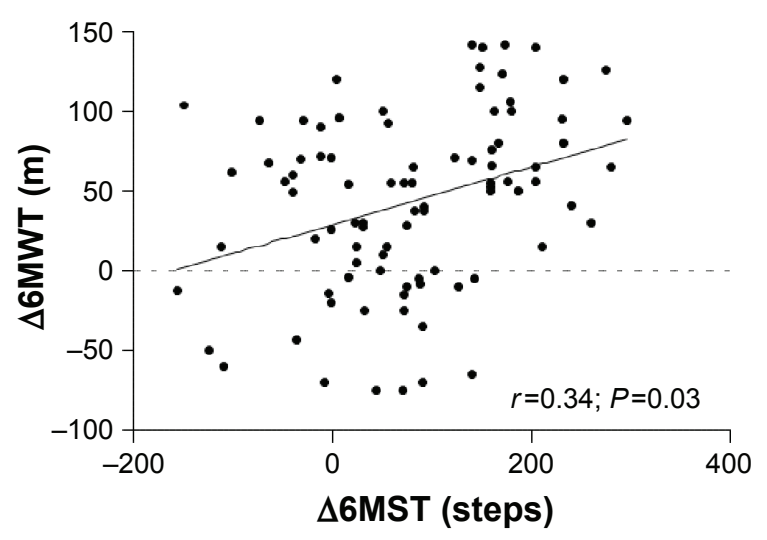

Figure 3 Correlation between improvement of the number of steps on the 6MST and improvement of the distance covered on the 6MWT after PR.

Abbreviations: 6MST, 6-minute stepper test; 6MWT, 6-minute walk test; PR, pulmonary rehabilitation.

Many studies have demonstrated the good sensitivity of the 6MWT at assessing the efficacy of outpatient or home PR in COPD patients. ${ }^{4,6}$ Lacasse et al ${ }^{3,42}$ reported gains of 56 and $48 \mathrm{~m}$ for outpatient PR and home PR, respectively. No consensus has been reached concerning the minimal clinically important difference (MCID) of the 6MWT: $54 \mathrm{~m}$ in the study by Redelmeier et $\mathrm{al}^{8}$ and $35 \mathrm{~m}^{9}$ and $26 \mathrm{~m}^{11}$ in more recent studies. A $14 \%$ relative improvement has also been proposed, but appears to be less sensitive than an absolute value of $25 \mathrm{~m} .{ }^{10}$ The gain of $42 \mathrm{~m}$ observed in this study is consistent with the data of the literature. ${ }^{8-11}$ Furthermore, a significant increase in the number of steps on the 6MST (from 488 to 570) was observed not only after outpatient PR (in agreement with previously published results in 30 COPD patients),${ }^{16}$ but also after home PR in a population of patients with idiopathic pulmonary fibrosis ${ }^{43}$ unselected patients with more severe chronic lung disease $(80 \%$ on long term oxygen therapy and/or noninvasive ventilation), ${ }^{17}$ and in COPD patients. ${ }^{18}$ The mean improvement of 79 steps on the 6MST in this study is superior to the 40-step MCID proposed by Pichon et $\mathrm{al}^{14}$ based on the analysis of the results of 62 COPD patients managed by inpatient PR. The performances on the two clinical exercise tolerance tests were significantly improved after PR: 79 steps on the $6 \mathrm{MST}$ and $42 \mathrm{~m}$ on the $6 \mathrm{MWT}$, and these improvements were significantly correlated with each other. Coquart et al ${ }^{16}$ suggested that familiarization with the 6MWT would have an impact on improved performance on the 6MST after PR due to a possible learning effect. However, it should be stressed that the patients in this study did not use the stepper as a retraining tool. The improvements observed on the 6MST were consequently the result of improvement of the subject's aerobic and muscular capacities. These results suggest that, 
like the $6 \mathrm{MWT},{ }^{4,6}$ the $6 \mathrm{MST}$ is a sensitive clinical exercise test to assess the efficacy of a PR program on the exercise tolerance of COPD patients.

This study was mainly limited by its retrospective nature. However, there were only a few data missing, and most of the variables were objective measurements collected from standardized tests. Almost half the patients were excluded from the study because all the required examinations were not performed on them. Although this could introduce a selection bias, there was no statistical difference between excluded and included patients concerning demographic, clinical, comorbidities, and pulmonary function data (data not shown).

\section{Conclusion}

This study demonstrates not only a correlation between the number of steps on the 6MST and the distance covered on the 6MWT, but also a correlation with power and $\mathrm{VO}_{2 \text { max }}$ of the CPET for COPD patients regardless of their stage of severity. The improvements on the 6MST and 6MWT observed after PR were also correlated, confirming the value of this new, sensitive, and reproducible test, which is easy to perform without any spatial constraints, for assessment of exercise tolerance in COPD patients, in routine respiratory medicine practice, and especially, before and after short- and long-term PR management.

\section{Disclosure}

JM Grosbois received financial support from Adair, France Oxygène, Homeperf, LVL, Orkyn, Santélys, SOS Oxygène, Sysmed, and VitalAire for home-based PR program. The authors report no other conflicts of interest in this work.

\section{References}

1. Vanfleteren LE, Spruit MA, Groenen M, et al. Clusters of comorbidities based on validated objective measurements and systemic inflammation in patients with chronic obstructive pulmonary disease. Am J Respir Crit Care Med. 2013;187(7):728-735.

2. Van Remoortel H, Hornikx M, Langer D, et al. Risk factors and comorbidities in the preclinical stages of chronic obstructive pulmonary disease. Am J Respir Crit Care Med. 2013;189(1):30-38.

3. Lacasse Y, Goldstein R, Lasserson TJ, Martin S. Pulmonary rehabilitation for chronic obstructive pulmonary disease. Cochrane Database Syst Rev. 2006;(4):CD003793.

4. Société de Pneumologie de Langue Française. Recommandations pour la pratique clinique. Prise en charge de la BPCO [Recommendation for the clinical practice management of COPD]. Rev Mal Respir. 2010;27(Suppl1): S1-S76, I-XXXI. French.

5. van Ranst D, Otten H, Meijer JW, van't Hul AJ. Outcome of pulmonary rehabilitation in COPD patients with severely impaired health status. Int J Chron Obstruct Pulmon Dis. 2011;6:647-657.

6. Spruit MA, Singh SJ, Garvey C, et al. An official American Thoracic Society/European Respiratory Society statement: key concepts and advances in pulmonary rehabilitation. Am J Respir Crit Care Med. 2013; 188(8):e13-e64.
7. Aguilaniu B, Wallaert B. EFX: De L'interprétation à La Décision Médicale. Paris, France: Margaux Orange; 2015.

8. Redelmeier DA, Bayoumi AM, Goldstein RS, Guyatt GH. Interpreting small differences in functional status: the six minute walk test in chronic lung disease patients. Am J Respir Crit Care Med. 1997;155(4):1278-1282.

9. Puhan MA, Mador MJ, Held U, Goldstein R, Guyatt GH, Schünemann HJ. Interpretation of treatment changes in 6-minute walk distance in patients with COPD. Eur Respir J. 2008;32(3):637-643.

10. Holland AE, Hill CJ, Rasekaba T, Lee A, Naughton MT, McDonald CF. Updating the minimal important difference for six-minute walk distance in patients with chronic obstructive pulmonary disease. Arch Phys Med Rehabil. 2010;91(2):221-225.

11. Puhan MA, Chandra D, Mosenifar Z, et al. The minimal important difference of exercise tests in severe COPD. Eur Respir J. 2011;37(4): 784-790.

12. ATS Committee on Proficiency Standards for Clinical Pulmonary Function Laboratories. ATS statement: guidelines for the six-minute walk test. Am J Respir Crit Care Med. 2002;166(1):111-117.

13. Holland AE, Rasekaba T, Fiore JF, Burge AT, Lee AL. The 6-minute walk distance cannot be accurately assessed at home in people with COPD. Disabil Rehabil. 2015;37(12):1102-1106.

14. Beekman E, Mesters I, Gosselink R, et al. The first reference equations for the 6-minute walk distance over a $10 \mathrm{~m}$ course. Thorax. 2014;69(9): 867-868.

15. Borel B, Fabre C, Saison S, Bart F, Grosbois J-M. An original field evaluation test for chronic obstructive pulmonary disease population: the six-minute stepper test. Clin Rehabil. 2010;24(1):82-93.

16. Coquart JB, Lemaitre F, Castres I, Saison S, Bart F, Grosbois J-M. Reproducibility and sensitivity of the 6-minute stepper test in patients with COPD. COPD. 2015;12(5):533-538.

17. Grosbois J-M, Le Rouzic O, Monge E, Bart F, Wallaert B. [Comparison of home-based and outpatient, hospital-based, pulmonary rehabilitation in patients with chronic respiratory diseases.] Rev Pneumol Clin. 2013; 69(1):10-17. French.

18. Grosbois JM, Gicquello A, Langlois C, et al. Long term evaluation of homebased pulmonary rehabilitation in patients with chronic obstructive pulmonary disease. Int J Chron Obstruct Pulmon Dis. 2015:10:2037-2044.

19. Rabe KF, Hurd S, Anzueto A, et al. Global strategy for the diagnosis, management, and prevention of chronic obstructive pulmonary disease: GOLD executive summary. Am J Respir Crit Care Med. 2007; 176(6):532-555.

20. Quanjer PH, Tammeling GJ, Cotes JE, Pedersen OF, Peslin R, Yernault JC. Lung volumes and forced ventilatory flows. Report Working Party Standardization of Lung Function Tests, European Community for Steel and Coal. Official Statement of the European Respiratory Society. Eur Respir J Suppl. 1993;16:5-40.

21. Miller MR, Hankinson J, Brusasco V, et al. Standardisation of spirometry. Eur Respir J. 2005;26(2):319-338.

22. Aguilaniu B, Richard R, Costes F, et al. Méthodologie et Pratique de l'Exploration Fonctionnelle à l'eXercice (EFX) [Cardiopulmonary exercise testing]. Rev Mal Respir. 2007;24(3 Pt 2):2S111-2S160. French.

23. American Thoracic Society; American College of Chest Physicians. ATS/ACCP statement on cardiopulmonary exercise testing. Am J Respir Crit Care Med. 2003;167(2):211-277.

24. Beaver WL, Wasserman K, Whipp BJ. A new method for detecting anaerobic threshold by gas exchange. J Appl Physiol 1985. 1986; 60(6):2020-2027.

25. Wasserman K, Whipp BJ, Koyl SN, Beaver WL. Anaerobic threshold and respiratory gas exchange during exercise. J Appl Physiol. 1973;35(2): 236-243.

26. Delourme J, Stervinou-Wemeau L, Salleron J, Grosbois JM, Wallaert B. Six-minute stepper test to assess effort intolerance in interstitial lung diseases. Sarcoidosis Vasc Diffuse Lung Dis. 2012;29(2): $107-112$.

27. Troosters T, Vilaro J, Rabinovich R, et al. Physiological responses to the 6-min walk test in patients with chronic obstructive pulmonary disease. Eur Respir J. 2002;20(3):564-569. 
28. Turner SE, Eastwood PR, Cecins NM, Hillman DR, Jenkins SC. Physiologic responses to incremental and self-paced exercise in COPD: a comparison of three tests. Chest. 2004;126(3):766-773.

29. Casas A, Vilaro J, Rabinovich R, et al. Encouraged 6-min walking test indicates maximum sustainable exercise in COPD patients. Chest. 2005;128(1):55-61.

30. Cote CG, Pinto-Plata VM, Marin JM, Nekach H, Dordelly LJ, Celli BR. The modified BODE index: validation with mortality in COPD. Eur Respir J. 2008;32(5):1269-1274.

31. McGavin CR, Gupta SP, McHardy GJ. Twelve-minute walking test for assessing disability in chronic bronchitis. Br Med J. 1976;1(6013): $822-823$

32. Carter R, Holiday DB, Stocks J, Grothues C, Tiep B. Predicting oxygen uptake for men and women with moderate to severe chronic obstructive pulmonary disease. Arch Phys Med Rehabil. 2003;84(8):1158-1164.

33. Luxton N, Alison JA, Wu J, Mackey MG. Relationship between field walking tests and incremental cycle ergometry in COPD. Respirology. 2008;13(6):856-862.

34. Guyatt GH, Sullivan MJ, Thompson PJ, et al. The 6-minute walk: a new measure of exercise capacity in patients with chronic heart failure. Can Med Assoc J. 1985;132(8):919-923.

35. Guyatt GH, Thompson PJ, Berman LB, et al. How should we measure function in patients with chronic heart and lung disease? JChronic Dis. 1985;38(6):517-524.

36. Pollock M, Roa J, Benditt J, Celli B. Estimation of ventilatory reserve by stair climbing. A study in patients with chronic airflow obstruction. Chest. 1993;104(5):1378-1383.
37. Villiot-Danger E. [A stairclimbing test in COPD patients assessment] Rev Mal Respir. 2009;26(5):530-536. French.

38. Jones SE, Kon SS, Canavan JL, et al. The five-repetition sit-to-stand test as a functional outcome measure in COPD. Thorax. 2013;68(11): $1015-1020$

39. Dal Corso S, Duarte SR, Neder JA, et al. A step test to assess exerciserelated oxygen desaturation in interstitial lung disease. Eur Respir J. 2007;29(2):330-336.

40. Swinburn CR, Wakefield JM, Jones PW. Performance, ventilation, and oxygen consumption in three different types of exercise test in patients with chronic obstructive lung disease. Thorax. 1985;40(8):581-586.

41. PessoaBV,ArcuriJF,Labadessa IG, CostaJN, Sentanin AC, DiLorenzo VA. Validity of the six-minute step test of free cadence in patients with chronic obstructive pulmonary disease. Braz J Phys Ther. 2014;18(3): 228-236.

42. Lacasse Y, Wong E, Guyatt GH, King D, Cook DJ, Goldstein RS. Metaanalysis of respiratory rehabilitation in chronic obstructive pulmonary disease. Lancet. 1996;348(9035):1115-1119.

43. Rammaert B, Leroy S, Cavestri B, Wallaert B, Grosbois J-M. Homebased pulmonary rehabilitation in idiopathic pulmonary fibrosis. Rev Mal Respir. 2011;28(7):e52-e57.

44. Pichon R, Beaumont M, Le Ber-Moy C, Péran L, Couturaud F. Détermination d'une différence minimale importante pour le stepper-test de six minutes chez les patients atteints de BPCO [Determination of a significant minimal difference for the 6 minute stepper-test in patients with COPD]. Rev Mal Respir. 2015;32:A75. French.
International Journal of COPD

\section{Publish your work in this journal}

The International Journal of COPD is an international, peer-reviewed journal of therapeutics and pharmacology focusing on concise rapid reporting of clinical studies and reviews in COPD. Special focus is given to the pathophysiological processes underlying the disease, intervention programs, patient focused education, and self management protocols.

\section{Dovepress}

This journal is indexed on PubMed Central, MedLine and CAS. The manuscript management system is completely online and includes a very quick and fair peer-review system, which is all easy to use. Visit http://www.dovepress.com/testimonials.php to read real quotes from published authors. 